\title{
The prevalence of asymptomatic malaria parasitemia and associated factors among adults in Dembia district, northwest Ethiopia, 2017
}

\author{
Mesafint Fekadu ${ }^{1}$, Melaku Kindie Yenit $^{2}$ and Ayenew Molla Lakew ${ }^{2 *}$
}

\begin{abstract}
Background: Malaria is still a leading cause of morbidity and mortality in many developing countries including Ethiopia. Its prevalence has been declining among Ethiopian adults, especially in Dembia district. However, it is still at the top of diseases list at the district. Hence, the study aimed to determine the prevalence and the factors that contribute to its being the major public health concern despite different preventive and control measures in place.

Methods: A community based cross-sectional study was conducted from October 11 to November 16, 2017. The multistage sampling technique was employed to select 832 study participants. A rapid diagnostic test were used to confirm the disease. Data were entered using Epi info version 7 and was analyzed by Statistical Package for Social Science (SPSS) version 20. The logistic regression model was performed to examine the association of factors with malaria parasite.

Results: Out of the 832 adults included in the study, 6.7\% (95\% Confidence Interval (Cl: 5.2-8.7)) were confirmed to be malaria parasite carriers. The dominant plasmodium species was Plasmodium falciparum [46 (82\%)]. According to the multivariable logistic regression analysis, male sex (Adjusted Odds Ratio ( $\mathrm{AOR}=4.5 ; 95 \% \mathrm{Cl}: 2.1-9.5$ ), adult age 15-19 years (AOR $=4.5 ; 95 \% \mathrm{Cl}: 2.1-9.7)$, travel history ( $\mathrm{AOR}=5 ; 95 \% \mathrm{Cl}: 2.34-12.25)$, and stagnant water around home $(A O R=3.7 ; 95 \% C l: 1.57-8.87)$ increased the probability of malaria infectivity, while Insecticidal Treated Nets (ITN) utilization (AOR $=0.2 ; 95 \% \mathrm{Cl}: 0.09-0.31)$ decreased it.

Conclusion: Malaria is still an important public health challenge among adults in the study area. Male sex, age 15-19 years, travel history, living around stagnant water, and not using ITN increased the probability of infection. Therefore, the District Health office and Health extension workers should work to increase ITN distribution and focus on reducing malaria breading sites through community participation.
\end{abstract}

Keywords: Malaria, Adult, Northwest Ethiopia

\section{Background}

Malaria is one of the most severe public health problems and the leading cause of death in many developing countries. Globally, there were an estimated 214 million new cases of malaria and 438,000 deaths in 2015. Of this, $88 \%$ of the cases and $90 \%$ of the deaths occurred in the African region [1]. In 2016, there were an estimated

\footnotetext{
* Correspondence: mayenew15@gmail.com

2Department of Epidemiology and Biostatistics, Institute of Public Health,

University of Gondar, Po.Box: 196, Gondar, Ethiopia

Full list of author information is available at the end of the article
}

216 million cases and 445,000 deaths attributable to the disease globally. About $85 \%$ of the estimated malaria cases (P.vivax) occurred in five countries that includes Ethiopia [2].

Ethiopia is generally considered as a low to moderate malaria transmission intensity country with about $75 \%$ of the land and $60 \%$ of the people is exposed. Due to the unstable and seasonal transmission of malaria in the country, the protective immunity of the population is generally low causing all age groups to be at risk [1]. Studies conducted in different parts of Ethiopia indicated that the prevalence

C The Author(s). 2018 Open Access This article is distributed under the terms of the Creative Commons Attribution 4.0 International License (http://creativecommons.org/licenses/by/4.0/), which permits unrestricted use, distribution, and reproduction in any medium, provided you give appropriate credit to the original author(s) and the source, provide a link to the Creative Commons license, and indicate if changes were made. The Creative Commons Public Domain Dedication waiver (http://creativecommons.org/publicdomain/zero/1.0/) applies to the data made available in this article, unless otherwise stated. 
of malaria in the country ranges from 2.8 to $28.1 \%$ [3-9]. In the 2014 annual report the national incidence of malaria was 3540 cases $/ 100000$ people. The highest $(610,486)$ case were reported in Amhara region with an annual incidence rate of 3866 per 100,000 [10].

Malaria imposes substantial costs on both individuals and governments. Direct costs (for example, illness, treatment, premature death) have been estimated to be at least USD 12 billion per year globally [11]. Despite substantial cost savings, malaria has placed a heavy economic burden on health systems in Africa. Since 2000, the average annual cost of case management alone has been estimated at nearly USD 300 million [1].

Ethiopia has achieved a remarkable progress in the fight against malaria in the last decade following the launching of the Health Extension Program in 2003 [12]. The major activities for malaria prevention and control focused on expanding vector control, strengthening case detection and treatment, increasing availability and use of Long-Lasting Insecticide-treated Nets (LLIN), and implementing Indoor Residual Spray (IRS) [13]. Despite the declining trend of the prevalence in Ethiopia including Dembia district, malaria is among top short listed diseases [12]. So far, studies conducted to ascertain malaria prevalence and associated factors were institution-based and are not adequately generalizable to communities. Therefore, this study determined the current prevalence of asymptomatic malaria parasitemia and associated factors among adults in the community. The study is valuable for indirectly assessing the effectiveness of interventions aimed at malaria eradication and/or prevention. The study is also expected to help policy makers redesign malaria control and elimination strategies.

\section{Methods}

\section{Study area and period}

A community based cross-sectional study was conducted on the residents of Dembia district, located in North Gondar zone, northwest Ethiopia, from October 11 to November 16, 2017. The total population of the district was about 321,856 of whom 159,962 (49.7\%) were male. The district had 45 (40 rural and 5 urban) malarious kebeles. The altitude of the district ranges from $1800 \mathrm{~m}-$ $2600 \mathrm{~m}$ above sea level. The climate of the district was $100 \%$ woina-dega, and annual rain fall ranged from 772 $\mathrm{mmHg}-1260 \mathrm{mmHg}$. Annual temperature ranged from 18 to 30 degree Celsius. The district had one hospital, 10 health centers, 40 health posts and 20 private clinics at its services.

\section{Sample size and sampling techniques}

All adults (age $>=15$ years) in Dembia district were taken as a source population, while all adult individuals in randomly selected kebeles were considered as a study participants. Any adult individuals who took anti-malarial drugs 2 weeks before the survey, severely ill and unable to respond were not included.

A sample of 310 adults was estimated using the single population proportion formula and considering a 95\% confidence level, $5 \%$ margin of error, and $28.1 \%$ prevalence of malaria infection [4]. Considering 95\% confidence level, $80 \%$ power, and 1:1 unexposed to exposed ratio, sample size was also estimated for different significant and pertinent factors for malaria infection, and stagnant water yielded a large sample (378). Then, by adding a $10 \%$ non-response rate and using a design effect of 2, 832 participants were estimated for the study.

A multistage sampling technique was used to select representative households. First a list of 45 kebeles was obtained from the District Health Office, at which $9(20 \%)$ were selected using the simple random sampling technique and considering as a primary sampling unit. Then the estimated sample was proportionally distributed to the selected kebeles based on their number of households and considering them as a secondary sampling unit. Finally, the lottery method was used to select any single household member for a rapid diagnostic test.

\section{Data collection procedures}

The dependent variable of this study was the malaria test result (Positive, Negative). The independent variables were age, sex, educational status, family size, knowledge about malaria (cause, prevention methods, mode of transmission, signs and symptoms), main source of drinking water, travel history, occupation, toilet facilities, outdoor activities, stagnant water, ITN possession, ITN utilization, and IRS.

Blood samples were drawn and tested for malaria presence using a Rapid Diagnostic Test (RDT). Carestart ${ }^{\text {th }}$ malaria Pf/Pv (HRP2/pLDH) Ag combo RDT was used. The validity of the kit was checked through 2 replicates of carestart $^{\text {tw }}$ malaria Pf/Pv (hrp2/pLDH) Ag combo RDT from each box with negative and positive clinical samples confirmed by microscopic examinations. In addition, a semi-structured questionnaire adapted from previous studies was administered to collect data on socio-demographic, economic and environmental factors, prevention methods, and knowledge relating to malaria infection.

Observations have been made on the possession and utilization of ITN and the availability of stagnant water around houses. The data were collected by 8 health extension workers and 2 laboratory technicians, supervised by 2 clinical nurses.

Before the actual data collection, a pretest was administered on $5 \%$ of the sample not included in the main study. Both data collectors and supervisors were trained for 3 days on how to approach study subjects and collect 
data. The supervisors and the principal investigator closely followed the daily completeness and appropriateness of the data collection. The validity of the kit was checked by testing 2 replicates of carestart ${ }^{\mathrm{Tw}}$ malaria Pf/ Pv (hrp2/pLDH) Ag combo RDT before the actual data collection. Knowledge of respondents in this study was measured considering respondents knowledge on the basic concepts of malaria prevention and control strategies such as causes, symptoms of malaria and means of prevention and control mechanisms. Accordingly, the mean score of respondents was used as to classify knowledge as good and poor.

\section{Data management and analysis}

Data were entered into Epi info version 7, exported and analyzed using SPSS version 20. Descriptive statistics, like the median with an interquartile range, frequencies, and percentages were employed. Cross-tabulations were plotted before both bivariate and multivariable logistic regression analyses were performed. Bi-variable and multi-variable logistic regression analyses were performed to examine the associations of covariates with malaria infection. All risk factors with $p$-value $<0.25$ at the bi-variable analysis were entered into the multi-variable analysis to control confounding effects. The associations between dependent and independent variables were measured and tested using Odds Ratio (OR) with a 95\% CI. The parsimonious model fitness was checked by Hosmer and Lemeshow goodness of fit test and a $P$-value of 0.67 was obtained.

\section{Results}

\section{Socio-demographic characteristics of participants}

A total of 832 individuals participated in this study with a response rate of $100 \%$. Four hundred thirty-seven $(52.5 \%)$ of the participants were female with about 547 (67.5\%) unable to read and write. The median age was 34 (Inter Quartile Range (IQR): 24-45) years. About $64.8 \%$ of the households had less than 5 members with the median family size of 4 (IQR: $3-6)$ (Table 1).

\section{Risk factor characteristics of study participants}

The majority (92\%) of the participants used household ITNs at bed-times. Out of those who had ITNs, $687(89 \%)$ always slept under mosquito nets, while only 277 (33\%) households sprayed chemicals in the last 6 months. Five hundred thirty (63.7\%) of respondents had poor knowledge about malaria signs, symptoms, and its prevention and control methods (Table 1).

\section{The prevalence of malaria infection}

Fifty-six $(6.7,95 \%$ CI: $0.052,0.087)$ of the participants had RDT confirmed malaria parasites in their blood samples. The dominant plasmodium species was Plasmodium falciparum (46(82\%)) followed by 5(9\%) Plasmodium vivax, and (Pf + Pv) 5(9\%) mixed infections.

\section{Factors associated with malaria infection}

After adjusting for potential confounding variables, being male sex was 4.5 times more likely to have malaria infections (AOR $=4.5,95 \% \mathrm{CI}: 2.1-9.5)$. Individuals in the age group of $15-19$ years were 4.5 times more likely to have malaria infections ( $\mathrm{AOR}=4.5,95 \% \mathrm{CI}$ : 2.1-9.7) compared to 20 and above age groups. Those who always slept under mosquito nets decreased the risk of malaria positivity by $80 \%$ (AOR $=0.2,95 \% \mathrm{CI}: 0.09-0.31$ ) Individuals who traveled away from residence had 5 times more chance of having malaria infections (AOR $=$ 5, 95\%CI: 2.34-12.25) compared to those who did not. Individuals who lived close to stagnant water $(\mathrm{AOR}=$ 3.7, 95\%CI: 1.57-8.87) were also significantly associated with malaria infection than those who did not (Table 2).

\section{Discussion}

This study showed that malaria is still a public health concern among the adult population of Dembia district. The study revealed that the overall malaria prevalence was $6.7 \%$ (95\% CI: 5.2-8.7). However, the studies conducted in Dilla town and its surrounding Gedeo zone [8] Hadiya zone [3], Chuchu and Wnago health center [4] and East Shewa zone of the Oromia regional state [9] found a much higher prevalence of malaria. This discrepancy might be due to differences of participants; the other studies were conducted on suspected febrile cases who came for some medical services only. Our finding is higher than that of a study conducted in Jimma town, southwest Ethiopia (5.2\%) [7]. This variation might be attributed to different data collection periods; in this study data were collected during the major malaria transmission season. It is also almost three times higher than the $2.8 \%$ of a study conducted in Jabi Tehnan district, Amhara Region [5]. The variations could be attributed to different climatic conditions for example, less rain fall and availability of surface water in the study areas serve as mosquito breeding sites.

In this study, Plasmodium falciparum which accounted for $82 \%$ of the cases was the dominant plasmodium species. This finding is in line with the malaria parasite distribution in Ethiopia [14]. It is also similar to those of studies conducted in Benna Tsemay district [15] and Nigeria [16]. Conversely, other studies conducted in East Shewa zone indicated that Plasmodium vivax was the dominant plasmodium species [9]. This might be so because Plasmodium falciparum is more widely distributed in most parts of Ethiopia. The possible discrepancy might be due to the fact that climate variation among study areas have effect on life cycle of parasite, parasite adaptation among Plasmodium vivax and falciparum. 
Table 1 Socio-demographic and individual characteristics of respondents in Dembia district, North West Ethiopia, 2017

\begin{tabular}{lll}
\hline Variables & Frequency & Percentage \\
\hline Age (in years) & & \\
$15-19$ & 75 & 9.0 \\
$>20$ & 757 & 91.0 \\
Sex & & \\
Female & 437 & 52.5 \\
Male & 395 & 47.5
\end{tabular}

Family size

$<5$

$>5$

539

293

Educational status

No education

Able to read and write

Sleeping area

Indoor

Outdoor

30

Outdoor activities before dawn and dusk

History of travel to malarious area

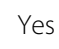

No

Availability of toilet facility

Yes

No

Cattle in the house

Yes

No

Stagnant water around home

Yes

No

ITN possession

Yes

No

Always sleep under mosquito net

Yes

No

IRS in the last 6 month

$$
\text { Yes }
$$

No

Source of water

Protected

Unprotected

Knowledge
Table 1 Socio-demographic and individual characteristics of respondents in Dembia district, North West Ethiopia, 2017 (Continued)

\begin{tabular}{cll}
\hline Variables & Frequency & Percentage \\
\hline Poor & 530 & 63.7 \\
Good & 302 & 36.3 \\
\hline
\end{tabular}

This study also revealed that the odds of asymptomatic malaria parasitemia among male adults were more than in females. This result is also supported by previous studies conducted elsewhere $[17,18]$. This might be due to the fact that in our setting, males are more exposed to outdoor activities than females and face increased risk of mosquito bit.

The odds of malaria infection among respondents in the age group of 15-19 years were higher compared with over 20 years ( $\mathrm{AOR}=4.5 ; 95 \% \mathrm{CI}: 2.1-9.7$ ). The finding is consistent with that of a study conducted in East Shewa which stated that being in the age group of 15-24 was more risks for malaria infection [9]. This might be due to the fact that participants in the 15 to 19 years groups are likely to have lower malaria sub-immunity than higher age groups. Moreover, higher exposure to outdoor activity of older adults before bed time might expose to malaria infections.

The utilization of ITN is a powerful vector control tool for reducing malaria transmission [13]. This study revealed that those who always slept under mosquito nets decreased the risk of malaria positivity compared to those who did not use ITN during bed time. This result is also supported by that of a study conducted in Hadiya zone which stated that those who did not use bed nets were 4.67 times more likely to be infected [3]. It is also supported by different studies conducted in different areas $[4,8,16,17,19]$. Environmental management for vector control is among the key components of the national malaria prevention and control strategy [13]. The study showed that individuals who had stagnant water around the house had a significantly increased risk of having malaria than those who had no such water. The result is also supported by that of a study conducted in south Ethiopia [4].

In this study, the odds of malaria infection among adults who had history of travel were higher than who did not travel away from their residence. This finding is similar with that of a study conducted in Jimma town, southwest Ethiopia [7]. This might be so because those who travel are less likely to use ITN and other protective techniques.

Though the study did its best to determine the prevalence of asymptomatic malaria parasitemia in the study setting, it is not free from some limitations. The cross-sectional nature of the study did not enable it to 
Table 2 Bi-variable and multi-variable regression analysis of covariates related to malaria positivity in Dembia district, North West Ethiopia, 2017

\begin{tabular}{|c|c|c|c|c|}
\hline \multirow[t]{2}{*}{ Variables } & \multicolumn{2}{|c|}{$\begin{array}{l}\text { Malaria test } \\
\text { positivity }\end{array}$} & \multirow[b]{2}{*}{ COR $(95 \% \mathrm{Cl})$} & \multirow[b]{2}{*}{ AOR $(95 \% \mathrm{Cl})$} \\
\hline & Positive & Negative & & \\
\hline \multicolumn{5}{|l|}{ Sex } \\
\hline Female & 10 & 427 & 1.00 & 1.00 \\
\hline Male & 46 & 349 & $5.6[2.8-11.3]$ & $4.5[2.10-9.50]^{*}$ \\
\hline \multicolumn{5}{|l|}{ Age } \\
\hline 15-19 & 15 & 60 & $4.4[2.3-8.3]$ & $4.5[2.10-9.70]^{*}$ \\
\hline$>=20$ & 41 & 716 & 1.00 & 1.00 \\
\hline \multicolumn{5}{|l|}{ Family size } \\
\hline$<5$ & 38 & 501 & 1.00 & \\
\hline$>=5$ & 18 & 275 & $0.9[0.48-1.54]$ & \\
\hline \multicolumn{5}{|c|}{ Educational status } \\
\hline Illiterate & 33 & 514 & 1.00 & \\
\hline Literate & 23 & 262 & $0.73[0.42-1.27]$ & \\
\hline \multicolumn{5}{|l|}{ Travel history } \\
\hline Yes & 15 & 31 & $8.8[4.40-17.56]$ & 5.3 [2.34-12.25] \\
\hline No & 41 & 745 & 1.00 & 1.00 \\
\hline \multicolumn{5}{|c|}{ Sleeping area } \\
\hline Indoor & 48 & 754 & 1.00 & 1.00 \\
\hline Outdoor & 8 & 22 & 5.7 [2.43-13.50] & $1.7[0.5-5.8]$ \\
\hline \multicolumn{5}{|c|}{ Outdoor activities } \\
\hline Yes & 28 & 328 & 1.4 [0.79-2.35] & \\
\hline No & 28 & 448 & 1.00 & \\
\hline \multicolumn{5}{|c|}{ Toilet facilities available } \\
\hline Yes & 30 & 507 & 1.00 & 1.00 \\
\hline No & 26 & 269 & $1.6[0.95-2.82]$ & 0.68 [0.35-1.29] \\
\hline \multicolumn{5}{|c|}{ Cattle in the house } \\
\hline Yes & 45 & 578 & 1.00 & \\
\hline No & 11 & 198 & $0.7[0.36-1.41]$ & \\
\hline \multicolumn{5}{|c|}{ Stagnant water around home } \\
\hline Yes & 13 & 45 & $4.911[2.46-9.79]$ & $3.7[1.56-8.87]^{*}$ \\
\hline No & 43 & 731 & 1.00 & 1.00 \\
\hline \multicolumn{5}{|c|}{ Always sleep under mosquito net } \\
\hline Yes & 26 & 661 & $0.15[0.09-0.26]$ & $0.2[0.09-0.31]^{*}$ \\
\hline No & 30 & 115 & 1.00 & 1.00 \\
\hline \multicolumn{5}{|l|}{$\mathrm{IRS}^{\mathrm{a}}$} \\
\hline Yes & 23 & 254 & $1.4[0.82-2.49]$ & $1.3[0.67-2.6]$ \\
\hline No & 33 & 522 & 1.00 & 1.00 \\
\hline \multicolumn{5}{|l|}{ Knowledge } \\
\hline Poor & 41 & 519 & $1.35[0.73-2.49]$ & \\
\hline Good & 15 & 257 & 1.00 & \\
\hline \multicolumn{5}{|c|}{ Source of drinking water } \\
\hline Protected & 33 & 522 & 1.00 & 1.00 \\
\hline
\end{tabular}

Table 2 Bi-variable and multi-variable regression analysis of covariates related to malaria positivity in Dembia district, North West Ethiopia, 2017 (Continued)

\begin{tabular}{|c|c|c|c|c|}
\hline \multirow[t]{2}{*}{ Variables } & \multicolumn{2}{|c|}{$\begin{array}{l}\text { Malaria test } \\
\text { positivity }\end{array}$} & \multirow[b]{2}{*}{ COR $(95 \% \mathrm{Cl})$} & \multirow[b]{2}{*}{$\operatorname{AOR}(95 \% \mathrm{Cl})$} \\
\hline & Positive & Negative & & \\
\hline Unprotected & 23 & 254 & $1.4[0.82-2.49]$ & $1.6[0.85-3.1]$ \\
\hline
\end{tabular}

show temporal relationships. In addition, since the verification of malaria parasitemia was done using rapid diagnostic tests, it might have detected false results that did not indicate the actual status of the respondents. Furthermore, variables that were not considered in this study, such as occupation, marital status and residence were the other limitations of the study. Despite the aforementioned limitations, the study was able to assess malaria prevalence and associated factors in the community. This enables to show the relative precise figure of the problem and associated factors in the community, and thus, the result can be adequately generalized for similar population.

\section{Conclusion}

Malaria, especially the predominant Plasmodium falciparum, is an important public health problem among the adult inhabitants of the study area. Males and those in the age group of 15-19years are highly vulnerable groups for malaria positivity. ITN utilization is a protective factor for malaria infections, and factors like travel history and availability of stagnant water around dwelling are the risk factors. Therefore, during the implementation of malaria prevention and control activities, attention should be given to males who travel and work away from home and to youngsters in the age range of 15-19 years to use the most possible malaria prevention mechanisms. The District Health Office and health extension workers should be directed to work to increase ITN distribution in the community. The District Health Office should also focus on reducing or eradicating malaria breading sites through community participation. Travelers should use ITN, repellents, and protective clothes at places of arrival.

\footnotetext{
Abbreviations

AOR: Adjusted odds ratio; Cl: Confidence interval; COR: Crude odds ratio; IQR: Inter quartile range; IRS: Indoor residual spray; ITN: Insecticidal treated nets; RDT: Rapid diagnostic test; SPSS: Statistical package for social science
}

\section{Acknowledgements}

Our thankfulness goes to University of Gondar for giving a chance to do this study. We are grateful to Ethiopian Public Health Association and Amhara regional health bureau for funding the research. We are also very grateful for data collectors and study participants who willingly took part in this study. 


\section{Funding}

There was no specific fund for this research.

\section{Availability of data and materials}

All relevant information is within the manuscript. The data upon which the result was based can be available up on the request.

\section{Authors' contributions}

MF designed the study, developed the proposal, participated in the data collection, performed analysis and interpretation of data and drafted the paper. MKY and AML assisted in the design of the study, proposal writing, data analysis, and interpretation of the study AML carried out the manuscript preparation. All authors reviewed and approved the final manuscript.

\section{Ethics approval and consent to participate}

Ethical clearance and permission to conduct the research was obtained from Institutional Review Board of University of Gondar. A verbal consent and informed voluntary assent were taken from each participant. The confidentiality of the participants was maintained by omitting the names during data collection. A participant with positive for malaria parasite was linked to the nearest health facilities for treatment according to national malaria guide line.

\section{Consent for publication}

Not applicable.

\section{Competing interests}

The authors declare that they have no competing interest.

\section{Publisher's Note}

Springer Nature remains neutral with regard to jurisdictional claims in published maps and institutional affiliations.

\section{Author details}

${ }^{1}$ North Gondar Zone Public Health Emergency Management, Gondar, Ethiopia. ${ }^{2}$ Department of Epidemiology and Biostatistics, Institute of Public Health, University of Gondar, Po.Box: 196, Gondar, Ethiopia.

\section{Received: 28 August 2018 Accepted: 9 November 2018}

Published online: 20 December 2018

\section{References}

1. World Malaria Report 2015. Available from: http://www.who.int/malaria/ media/world-malaria-report-2015/en/. Accessed 22 May 2018.

2. World Health Organization. World malaria report 2016. Geneva: World Health Organization; 2016. p. 2017.

3. Delil RK, Dileba TK, Habtu YA, Gone TF, Leta TJ. Magnitude of malaria and factors among febrile cases in low transmission areas of Hadiya zone, Ethiopia: a facility based cross sectional study. PLoS One. 2014;11(5): e0154277.

4. Belete EM, Roro AB. Malaria Prevalence and Its Associated Risk Factors among Patients Attending Chichu and Wonago Health Centres, South Ethiopia. 2016;16(4):185-9.

5. Ayalew S, Mamo H, Animut A, Erko B. Assessment of current malaria status in light of the ongoing control interventions, socio- demographic and environmental variables in Jiga area, Northwest Ethiopia. PLoS One. 2013; 11(1):e0146214.

6. Graves PM, Richards FO, Ngondi J, Emerson PM, Shargie EB, Endeshaw T, et al. Individual, household and environmental risk factors for malaria infection in Amhara, Oromia and SNNP regions of Ethiopia. Trans R Soc Trop Med Hyg. 2009;103(12):1211-20.

7. Alemu A, Tsegaye W, Golassa L, Abebe G. Urban malaria and associated risk factors in Jimma town, south-west Ethiopia. 2010;10:173.

8. Molla E, Ayele B. Prevalence of Malaria and Associated Factors in Dilla Town and the Surrounding Rural Areas, Gedeo Zone, Southern Ethiopia. Bacteriol Parasitol. 2014;6:5.

9. Tadesse F, Fogarty AW, Deressa W. Prevalence and associated risk factors of malaria among adults in east Shewa zone of Oromia regional state, Ethiopia: a cross-sectional study. BMC Public Health. 2018:25:18.

10. FmOH. HSDP IV annual performance report of Ethiopia. 2014/2015.
11. Control CfD, Prevention. CDC. 2016. HIV Surveillance Supplemental Report. 2017;21(4).

12. PMI. Malaria operational plan FY 2016. 2015.

13. $\mathrm{FMOH}$. National malaria guide lines. 2012.

14. Organization WH. World malaria report, 2015. Geneva: WHO, 2015; 2017.

15. Debo GW, Kassa DH. Prevalence of malaria and associated factors in Benna Tsemay district of pastoralist community, southern Ethiopia. Trop Dis Travel Med Vaccines. 2016;2:16 December 2011 to January 2012;2(16).

16. Dawaki S, HM AM, Ithoi I, Ibrahim J, Atroosh WM, Abdulsalam AM, et al. Is Nigeria winning the battle against malaria? Prevalence, risk factors and KAP assessment among Hausa communities in KanoState. Malar J. 2016:15:351 May and June 2013.

17. Ayele DG, Zewotir TT, Mwambi HG. Prevalence and risk factors of malaria in Ethiopia. Malaria J. 2012;11(1):195.

18. Ferede G, Worku A, Getaneh A, Ahmed A, Haile T, Abdu Y, et al. Prevalence of malaria from blood smears examination: a seven-year retrospective study from Metema hospital, Northwest Ethiopia. Hindawi Publishing Corporation Malaria Research and Treatment. https://doi.org/10.1155/2013/704730. September 2006 to August 2012;2013.

19. Mugwagwa N, Mberikunashe J, Gombe NT, Tshimanga M, Bangure D, Mungati M. Factors associated with malaria infection in Honde valley, Mutasa district, Zimbabwe, 2014: a case control study. BMC Res Notes. 2015; 8:829 13 January 2014 to 26 January 2014.

\section{Ready to submit your research? Choose BMC and benefit from:}

- fast, convenient online submission

- thorough peer review by experienced researchers in your field

- rapid publication on acceptance

- support for research data, including large and complex data types

- gold Open Access which fosters wider collaboration and increased citations

- maximum visibility for your research: over $100 \mathrm{M}$ website views per year

At BMC, research is always in progress.

Learn more biomedcentral.com/submissions 